\title{
ÜBER DIE INTENSITÄTEN DER BANDENSPEKTREN DER PHOSPHORE
}

\author{
Inaugural - Dissertation \\ zur Erlangung der Doktorwürde
}

einer hohen naturwissenschaftlich-mathematischen Fakultät der Ruprecht-Karls-Universität zu Heidelberg

Vorgelegt von

HEINZ NITKA aus Mannheim 
Tag der mündlichen Prüfung: 28. Juli 1932.

Erschienen in: Annalen der Physik, 5. Folge, Band 16, 1933.

Gedruckt mit Genehmigung der naturwissenschaftlichmathematischen Universität Heidelberg.
Dekan:
Referent:

K. Freudenberg

F. Schmidt

1932.

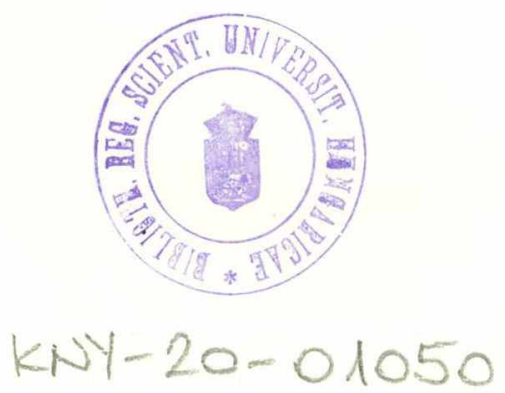




\section{Inhaltsangabe.}

I. Eine graphische Zerlegungsmethode der Intensitätskurven von Emissionen der Erdalkaliphosphore liefert die Abhängigkeit der Intensitäten der Emissionsbanden vom Metallgehalt und von der Herstellungstemperatur des Phosphors. Die beobachteten Einzelbanden liegen an den Stellen im Spektrum, die sich aus den Seriengesetzen von F. Schmidt für Banden erregender Absorption errechnen lassen.

II. Versuche bei monochromatischer Anregung haben das Ergebnis, daß die Intensität einer Einzelbande im wesentlichen davon abhängt, in welchem Spektralgebiet die erregende Lichtabsorption erfolgt.

III. Der Abklingungsverlauf der maximalen Intensität einer Einzelbande wird untersucht. Die Abklingungskurve läßt sich nicht durch eine einfache Exponentialfunktion darstellen; die Halbwertsbreite einer Einzelbande bleibt während der Abklingung stets dieselbe. Ferner können die Abklingungsversuche das Auftreten einer „verbotenen" Emissionsbande erklären.

IV. Es wird eine Verletzung des Stokes'schen Gesetzes im Nachleuchten der Phosphore beobachtet und gedeutet.

\section{Lebenslauf.}

Ich, Heinz Nitka, wurde am 22. Oktober 1909 als Sohn des Bezirksarztes Dr. Leopold Nitka und dessen Ehefrau Else, geb. Manz zu Mannheim geboren. Ich besitze die badische Staatsangehörigkeit. Nach Besuch der Vorschule trat ich Herbst 1919 in das humanistische Gymnasium Heidelberg ein, an dem ich Ostern 1928 die Reifeprüfung ablegte. Seit diesem Zeitpunkt bin ich als Student der Physik, Mathematik, Chemie und Astronomie an den Universitäten Heidelberg und Freiburg i. Br. immatrikuliert gewesen. 
